\title{
KONSTRUKSI POSTMODERN DALAM NOVEL LARUNG
}

\author{
Pujiharto \\ Jurusan Sastra Indonesia \\ Fakultas Ilmu Budaya UGM
}

\begin{abstract}
This research study intends to reveal the extent to which Larung (2001), as a recent Indonesian novel, shows postmodern features, especially in its construction, concerning the worlds under erasure and the Chinese box worlds.

The theory adopted in the study is that of postmodern fiction by Brian McHale. The method employed is semiotics by Hurshovsky. The theory and method are based on the assumption that postmodern fiction is ontological in nature. This is different from modern fiction, which is epistemological in nature. According to McHale, the ontological nature comprises zones, construction, words, and groundings. This study investigates, in particular, the construction in Larung.

The research findings show that in Larung there are features classified by McHale into construction, covering the worlds under erasure and the Chinese box worlds. In the former, Larung explores the features proposed by McHale, namely something always happening, something always existing, excluded middles, forking paths, and a sense of a (non) ending. In the latter Larung also explores features proposed by McHale, namely moving toward infinite regression, trompe-l'oell, strange loops, characters in search of an author, abysmal fictions, and something real. However, in terms of moving toward infinite regression Larung shows opposite features; it does not narrate things backward continuously, but it moves backward and forward to the present. Therefore, Larung can be classified as novel with a postmodern construction.
\end{abstract}

Key Word: postmodern, construction, and ontological

A. Pendahuluan

\section{Latar Belakang}

Sebagai istilah, postmodemisme telah muncul pada tahun 1930-an dalam dunia seni. Istilah tersebut digunakan oleh Federico de Onis untuk menunjukkan reaksi minor terhadap modemisme (Featherstone, 1993:9; Sugiharto, 1996:24). Aliran pemikiran tersebut kemudian mengalami perkembangan secara terus-menerus dan mencapai puncak pembicaraan yang paling ramai pada tahun 1970-an (Huyssen, 1990:356-357). Kemunculan aliran tersebut merupakan penanda bagi terjadinya transformasi besar dalam wilayah sosial budaya yang melanda dunia yang membedakannya dari era sebelumnya (Sarup, 1993:129).

Di Indonesia, pembicaraan tentang tema tersebut baru gencar dilakukan pada tahun 1990-an setelah Nirwan Dewanto membacakan makalahnya yang berjudul "Kebudayaan Indonesia: Pandangan 1991" dalam Kongres Kebudayaan, 29 Oktober s.d. 3 November 1991. Dalam makalah itu, Nirwan mengemukakan pentingnya mengubah cara pandang terhadap kebudayaan dari yang semula dilihat dalam kerangka narasi besar ke satuan-satuan kecil. Menurutnya, gerak 
kebudayaan ditentukan oleh gerak satuan-satuan kecil itu.

Setelah Nirwan Dewanto menyampaikan gagasannya itu, seminar tentang postmodemisme pun dengan sangat gencar digelar di berbagai institusi perguruan tinggi di Indonesia. Roland Robertson (1996:127) mengemukakan bahwa pada pertengahan tahun 1990an, isu globalitas meledak di lingkungan akademik, melintasi wilayah-wilayah disiplin konvensional dalam cara-cara yang membingungkan. Tampaknya, isu postmodernisme yang melingkupi berbagai wilayah disipliner adalah bagian dari globalitas yang dikemukakan Robertson tersebut.

Tulisan dan polemik tentang postmodernisme juga bermunculan di berbagai majalah dan koran. Berbagai makalah, tulisan, dan buku tentang postmodernisme tersebut sebagian besar mengungkap kaitannya dengan proses transformasi sosial dan budaya yang berlangsung di Indonesia.

Sebagai bagian dari karya budaya, sastra Indonesia tampaknya juga tidak bisa melepaskan diri dari kecenderungan menggejalanya pemikiran postmodern di atas. Bahkan, tanpa disadari, kecenderungan postmodern dalam dunia sastra telah lebih dulu ada sebelum aliran pemikiran itu masuk di Indonesia. Namun, pembicaraan kecenderungan tersebut baru mencuat ke permukaan seiring dengan kemunculan pemikiran tersebut. Dengan kata lain, kecepatan perkembangan dalam dunia sastra melampaui perkembangan dalam pemikiran.

Dalam genre cerpen, kecenderungan postmodern itu, misalnya, secara kuat tampak dalam kumpulan cerpen Godlob (1974), Adam Ma'rifat (1982), Berhala (1992), Gergasi (1994), Setangkai Melati di Sayap Jibril (2002) karya Danarto; Saksi Mata (1994), Negeri Kabut (1996),
Matinya Seorang Penari Telanjang (2000) karya Seno Gumira Ajidarma. Dalam genre novel, kecenderungan postmodern itu, misalnya, secara kuat tampak dalam Kering (1972), Kooong (1975), Ziarah (1969), dan Merahnya Merah (1968) karya Iwan Simatupang; Telegram (1973), Stasiun (1977) karya Putu Wijaya; Olenka (1983), Rafilus (1988), Ny. Talis Kisah Mengenai Madras (1996) karya Budi Darma; Saman (1998), Larung (2001) karya Ayu Utami; Asmaraloka (1999) karya Danarto. Penelitian ini akan memfokuskan pada salah satunya, yaitu Larung karya Ayu Utami.

\section{Tujuan Penelitian}

Penelitian ini memiliki dua tujuan, yaitu tujuan teoretis dan tujuan praktis. Secara teoretis, penelitian ini berusaha menjawab permasalahan yang muncul di atas, yaitu tentang konstruksi postmodern dalam novel Larung. Sebagaimana dikemukakan McHale, hal-hal yang terlingkup dalam konstruksi postmodern adalah "Dunia-Dunia di Bawah Penghapusan" dan "Dunia-Dunia Kotak Cina". Oleh karena itu, secara spesifik penelitian ini akan mendeskripsikan ciri-ciri keduanya yang terdapat dalam novel Larung.

Secara praktis, penelitian ini bertujuan menerapkan dan mengenalkan teori fiksi postmodern yang dalam dunia ilmu pengetahuan di Indonesia, khususnya ilmu sastra, masih dianggap baru.

\section{Landasan Teori}

Untuk menjawab masalah di atas, penelitian ini menggunakan teori yang dikemukakan oleh Brian McHale dalam buku Postmodernist Fiction (1991) yang penulis sebut dengan teori fiksi postmodern. Menurut McHale (1991:10), dominan fiksi postmodern adalah bersifat ontologis. Hal itu dioposisikan dengan dominan fiksi modem yang bersifat epistemologis (McHale, 1991:9). 
Sehubungan dengan hal itu, ada beberapa konsep yang penting dijabarkan, yaitu (1) postmodernisme, (2) dominan, dan (3) ontologi.

Menurut McHale (1991:4), postmodernisme adalah istilah yang acuannya tidak ada karena ia adalah suatu konstruksi. Karenanya, ada berragam postmodernisme. Yang penting menurut McHale (1991:4-5) adalah bahwa konstruksi postmodernisme yang dibangun memiliki konsistensi din dan koherensi internal, ruang lingkup yang tidak begitu luas dan tidak begitu sempit, dan produktif.

Dalam hal konsep postmodernisme, McHale mengacu pada pendapat Ihab Hassan, yang menekankan istilah tersebut pada awalan dan akhirannya: postmodemisme. Isme di situ bukan sekedar dipahami sebagai pembagian kronologis, tetapi sebuah sistem yang terorganisir, suatu puitika. Pada saat yang sama istilah itu mengidentifikasi apa yang dimaksud dengan post. Postmodernisme bukanlah post modern, melainkan post modernisme. Jadi, secara harfiah, puitika postmodemisme adalah puitika yang menjadi pengganti/penerus, a tau mungkin reaksi terhadap, puitika modernisme awal abad ke-20 (McHale, 1991:5).

Dengan awalan post, yang ditekankan adalah elemen konsekuensi logis dan historis daripada posterioritas temporal belaka. Postmodernisme terjadi dari modernisme daripada terjadi setelah modernisme (McHale, 1991:5). Postmodernisme bukan hanya posteritas (yang kemudian) dari modernisme, tetapi di antara keduanya ada hubungan konsekuensialitas historis.

Untuk menjelaskan hubungan itu, dibutuhkan suatu alat, yaitu dominan. McHale mengambil konsep "dominan" ini dari Jurij Tynjanov, seorang formalis Rusia, yang kemudian diuraikan secara panjang lebar oleh Roman Jacobson dalam tulisan berjudul "The Dominant" (dalam Language in Literature, 1994:4146). Dengan konsep dominan akan diketahui kecenderungan yang terdapat dalam karya fiksi karena dominan adalah yang mengatur, menentukan, dan mentransformasikan komponen-komponen yang tampak dengan jelas. Dominanlah yang menjamin integritas strukturnya. Dominan-dominan yang berbeda bisa dibedakan berdasarkan tingka tan, ruang lingkup, dan fokus analisisnya. Dengan dominan ini akan diketahui proses evolusi yang terjadi dalam karya fiksi. Dengan proses evolusi itu, elemenelemen yang semula sekunder bisa berubah menjadi penting dan primer, demikian pula sebaliknya (McHale, 1991:6-8).

Ontologis adalah pensifa tan kata ontologi. McHale mengacu pada pendapat Thomas Pavel dalam mendefinisikan ontologi, yaitu a description of a universe (deskripsi tentang sebuah semesta). Dengan a universe (sebuah semesta) -bukan the universe (semesta)-, maka dimungkinkan untuk mendeskripsikan beberapa semesta. Hal itu berarti bahwa secara potensial terdapat pluralitas semesta (McHale, 1991:27).

Dengan penjelasan ketiga konsep tersebut, maka menjadi jelas pula apa yang dimaksud dengan "dominan fiksi postmodern bersifat ontologis". Karena ada asumsi bahwa karya fiksi adalah sebuah sistem terstruktur, seperangkat hierarkis sarana artistik yang tertata secara teratur (McHale, 1991:6), maka dalam rumusan "dominan fiksi postmodern bersifat ontologis" terkandung pengertian bahwa karya fiksi merupakan sistem tanda. Ketandaan itu berkaitan dengan sifat ontologis yang merupakan ciri kepostmodernan. Sementara itu, ciriciri kepostmodernan tidak muncul dari kekosongan historis, tetapi terhasil dari 
hubungan oposisi statis dengan ciri-ciri kemodernan. Oleh karena itu, dalam upaya menjelaskan dominan ontologis fiksi postmodern, penting juga diketahui serba sedikit dominan epistemologis fiksi modern. Untuk itu, McHale (1991:39) menerapkan model semiotika dari Benjamin Hrushovsky.

Sebagai perbandingan, M. Gottdiener (1994:155), dalam tulisan "Semiotics and Postmodernism" menulis bahwa mengetahui semiotika adalah esensial untuk mengapresiasi postmodernisme. Bukan hanya karena argumen-argumen para pemikir postmodern terkenal seperti Derrida mendasarkan pada pengetahuan semiotika, tetapi seluruh lintasan pemikiran yang mulai dengan poststrukturalisme menggambarkan kritikkritik internal model-model semiotika. Dengan demikian, semiotika adalah inheren di dalam kajian postmodemisme Sebelum lebih lanjut diuraikan semiotika Hrushovsky, terlebih dahulu penting dilanjutkan uraian tentang ontologi. Pengertian ontologi sebagaimana diuraikan di atas adalah bersifat umum. Sifat itu tidak bisa menunjukkan bagaimana kepostmodernan karya sastra. Untuk bisa mencapai tujuan tersebut, diperlukan konsep ontologi yang bersifat khusus yang berkaitan dengan sastra. Untuk hal itu, McHale (1991:2738) mengemukakan beberapa teori ontologi klasik dalam puitika, dari Renaisance melalui romantika Jerman sampai Roman Ingarden dan teoretikus kontemporer mengenai "dunia yang mungkin". Teori-teori tentang ontologi sastra inilah yang kemudian menjadi penopang bagi penjelasan ciri-ciri kepostmodernan karya fiksi.

Dalam melihat karya fiksi, puitika Renaisance atau pandangan heterokosmos membedakan antara yang nyata dengan yang fiksi, dunia fiksi dianggap sebagai otherness, terpisah dari dunia pengalaman nyata. Implikasinya, terdapat batas wilayah ontologis di antara keduanya. Akan tetapi, karena hal itu bukan berarti tidak ada kaitan antara dunia nyata dengan dunia fiksi, maka dibutuhkan teori heterokosmos yang dimodifikasi, yaitu teori yang mengakui adanya semacam tumpang tindih tertentu atau interpenetrasi antara heterokosmos dan yang nyata. McHale (1991:28) mengacu pada pendapat Benjamin Hrushovsky yang mengatakan bahwa semua teks sastra mengandung struktur acuan yang berlapis (double decker). Teks sastra paling tidak memproyeksikan satu bidang acuan yang bersifat internal, sebuah semesta atau kontinum semantik (secara bebas, sebuah dunia) yang dikonstruksi di dalam dan oleh teks itu sendiri. Selain itu, teks-teks itu mau tidak mau mengacu keluar dari bidang internalnya menuju satu bidang referensi eksternal: dunia yang objektif, tubuh fakta historis, atau teori ilmiah, ideologi atau filsafat, teks-teks lain, dan sebaga inya.

Kedua, pandangan romantika Jerman yang melihat adanya analogi antara pengarang dan Tuhan melihat bahwa pengaranglah yang sesungguhnya selalu menguasai derajat ontologis yang superior terhadap derajat yang diproyeksikannya, diri fiksionalnya, dan karena itu, secara ganda superior terhadap dunia fiksi. Penyair romantik yang disamakan dengan Tuhan, bersifat imanen dan transenden, baik dalam heterokosmosnya dan di atasnya, secara terus-menerus ada sekaligus tidak ada. Akan tetapi, karena dunia fiksi kini mendapatkan pembuat yang dapat dilihat, maka status karya sastra bukan lagi sebagai cerminan alam, tetapi menjadi artefak, benda ciptaan yang tampak (McHale, 1991:29-30).

Ketiga, pandangan Roman Ingarden. Pandangan ini melihat bahwa 
kompleksitas karya sastra, menurut Ingarden (McHale, 1991:3033), pertamatama terletak pada keheteronomousannya, otonom pada dirinya sendiri dan sekaligus tergantung pada tindak konstitutif kesadaran pembaca. Kedua, karya sastra secara ontologis tidak seragam atau monolitik, tetapi poliponik, terstratifikasi. Setiap lapisnya memiliki status ontologis yang agak berbeda dan berfungsi berbeda dalam bangunan keseluruhan ontologis itu. Ingarden membedakan empat strata, yaitu strata bunyi kata, strata unit-unit arti, strata objek yang disajikan, dan strata aspekaspek yang terskema.

Keempat, pandangan dunia yang mungkin (McHale, 1991:33-36). Dengan mengacu pada logika klasik yang mengenal tiga modalitas: keutamaan, kemungkinan, dan kemustahilan, McHale mengatakan bahwa proposisi-proposisi dalam fiksi diatur oleh modalitas kemungkinan yang di dalamnya terjadi ketegangan keyakinan dan ketidakyakinan. Dunia yang mungkin tergantung pada sikap proposisi seseorang. Agar dunia-dunia itu mungkin, mereka harus diyakini, dibayangkan, diharapkan, dan sebagainya oleh beberapa agen manusia. Tokoh-tokoh di dalam dunia fiksi juga mampu memungkinkan sikapsikap proposisional dan memproyeksikan dunia yang mungkin.

Selain merumitkan struktur ontologis internal sebuah fiksi, pandangan dunia mungkin melemahkan batas atau bingkai eksternalnya. Berbeda dari teori mimetik klasik dan pandangan ahli logika dan filsuf bahasa yang lebih menekankan batas antara dunia nyata dan dunia fiksi, teori dunia yang mungkin justru mengaburkan batasbatas eksternal fiksi. Epidermis fiksi bukanlah sesuatu yang tidak dapat ditembus, tetapi sebuah membran semipermeabel (selaput semi tembus). Selain itu, dunia mungkin fiksi dan dunia nyata, dua atau lebih dunia fiksi yang berbeda, tempatnya di antara keseluruhan wilayah ontologi-ontologi "tidak nyata (unreal)" dan "quasi-real" dalam kebudayaan yang ada, tidak terelakkan saling bertumpang-tindih.

Keempat teori ontologi sastra di a tas dipergunakan untuk menjelaskan kepostmodernan karyakarya fiksi dalam batas-batas yang sesuai dengan tema masing-masing ontologi sastra itu sendiri dan kemungkinan derivatderivatnya. Hal itu dilakukan McHale karena fiksi yang ditelitinya becermin pada realitas yang plural yang disebut dengan lanskap ontologis pluralistik dan anarkistik (McHale, 1991:37).

Realitas yang plural itu menurut McHale (1991:38) mengacu pada kebudayaan industri maju. Salah satu bentuk lanskap ontologis ini adalah penyerapannya oleh realitas sekunder, khususnya fiksi-fiksi media massa, dan salah satu penjelasan yang sangat tipikal keanggotaan budaya ini, yaitu transisi salah satu dari duniadunia fiksional ini pada realitas puncak kehidupan seharihari, atau dari realitas puncak kehidupan sehari-hari ke fiksi. Dengan demikian, ada asumsi bahwa realitas yang plural memiliki hubungan berbanding lurus dengan ontologi yang plural.

Dalam menjelaskan kepostmodernan karya fiksi yang merupakan cermin dari realitas yang plural dan karenanya merupakan suatu bentuk lanskap ontologis yang juga plural itu, McHale (1991:39) menggunakan model semiotika tiga dimensi dari Hrushovsky dengan mengubahnya pada bagian-bagian yang dirasa perlu. Model semiotika tersebut meliputi dimensi dunia yang direkonstruksi, kontinum teks, dan pembicara, suara, dan posisi. Di dalam buku Postmodernist Fiction ketiga dimensi itu dirumuskan ke dalam subsubjudul "Duniadunia", "Kata-kata", dan "Konstruksi". 
Karena alasan tertentu, urutan itu dibalik menjadi "Dunia-dunia", "Konstruksi", dan "Kata-kata".

Selain itu, McHale (1991:39-40) juga mempertimbangkan bagaimana fiksi postmodern mengeksploitasi "dasar" ontologis demi tujuannya sendiri, yang hal itu diuraikan dalam bagian "Pendasaran".

\section{B. Metode Penelitian}

Subjek penelitian ini adalah novel Larung karya Ayu Utami, yang diterbitkan oleh penerbit Kepustakaan Populer Gramedia bekerja sama dengan Jurnal Kebudayaan Kalam, 2001. Selain itu, dibutuhkan juga data pendukung yang meliputi hasil-hasil penelitian yang pernah dilakukan, tulisan-tulisan, baik dalam bentuk buku atau artikel yang membicarakan subjek penelitian.

Langkah-langkah yang dilakukan dalam penelitian ini adalah sebagai berikut. Pertama, mengumpulkan data, baik data primer maupun sekunder yang dibutuhkan dalam penelitian ini. Kedua, melakukan pembacaan terhadap data tersebut. Ketiga, melakukan analisis dengan cara deskriptif, yaitu diuraikan ciri-ciri konstruksi postmodern novel Larung.

\section{Hasil Penelitan dan Pembahasan}

Setelah dilakukan identifikasi, di dalam novel Larung ditemukan adanya ciri-ciri kepostmodernan, khususnya berkaitan dengan konstruksinya. Di dalam novel Larung ditemukan adanya bentuk-bentuk cerita yang merupakan ciri dari dunia-dunia di bawah penghapusan (bagian 2).

Tampak pada pernyataan Larung tentang Adnjani. "Lama-lama aku tahu ia telah lama mati" (h. 12), padahal senyatanya Adnjani belum mati. Kematian Adnjani adalah peristiwa yang dihapus, dan kehidupannya, meskipun tubuhnya sudah kurus dan kering kerontang, adalah keadaan yang nyata.

Dengan gambaran serupa itu, pada diri Adnjani menyatu sekaligus ontologi kehidupan dan kematian. Adnjani tidak sepenuhnya hidup dan tidak sepenuhnya mati. Adnjani hidup dalam kematian dan mati dalam kehidupan.

Juga tampak pada halaman 31, yang menggambarkan terjadinya hujan yang telah berlangsung, tetapi bisa dipergikan oleh Suprihatin.

Tampak pada halaman 185 yang menggambarkan Saman yang sedang berada dalam situasi kesadaran yang saling bertabrakan. Hubungannya dengan Yasmin yang sampai pada hubungan seks telah meninggalkan beban yang cukup berat dalam pikirannya hingga bertabrakan dengan ingatannya tentang ibunya yang begitu dicintainya. Dunia sadar kadang dihapus oleh dunia bawah sadar atau dunia mimpi, dan sebaliknya. Goyangan dua struktur ontologis itu menjadikannya saling menghapus.

Juga tampak pada halaman 186 yang menggambarkan kekakacuan Saman antara apakah ia teringat atau bukan teringat tentang gagak yang tak berhenti hinggap yang terkacau dengan wajahnya sendiri. Keduanya berkelapkelip silih berganti: wajahnya kadang dihapus oleh gagak, dan sebaliknya.

Tengah-tengah yang dikeluarkan, cerita-cerita bercabang, tampak pada halam 6-7, yang berisi sebuah cerita yang cukup panjang tentang dunia hantu yang pernah dialami oleh seorang tukang becak. Cerita ini cukup panjang sehingga tampil sebagai cerita sendiri yang menyimpang dari cerita utamanya. Pencabangan cerita ini pada gilirannya memunculkan tengah-tengah, yaitu pada pencabangan itu sendiri.

Tengah-tengah yang dikeluarkan, cerita bercabang, juga tampak pada hal- 
aman 36-40. Pada halaman tersebut Suprihatin bercerita tentang "mereka yang dikalahkan", yang sebenamya merupakan cerita panjang dari masa lalu dan mereka memiliki mimpimalam hari.

Munculnya cerita bercabang ini menghadirkan tengah-tengah, persimpangan antara cerita Suprihatin dengan Larung yang sedang mencari cupu dengan cerita Suprihatin tentang mereka yang dikalahkan dan memiliki mimpi malam hari.

Tengah-tengah yang dikeluarkan, cerita bercabang juga muncul pada halaman. 77 s.d. 95. Di dalam penggal cerita itu diceritakan tentang perbincangan antara Cok dengan Yasmin dan sudut pandang Cok. Sebagai sebuah perbincangan, bila mengikuti perspektif modern atau struktural, mestinya cerita itu berlangsung lurus antara Cok dan Yasmin, tidak akan ada digresi. Akan tetapi, di dalamnya justru sering sekali dimunculkan digresi. Ada beberapa jenis digresi yang dimunculkan, yaitu (1) suara hati Cok tentang Yasmin (h. 78, 79-80, 82-84, 86-87, 89-90), (2) cerita Cok tentang tokoh lain (h. 87-89, 91-93, 95). Dengan pola penceritaan yang seperti itu, cerita dari h. 77 s.d. 95 tampak sebagai cerita-cerita bercabang: cabang pertama adalah cerita antara Cok dan Yasmin yang terus berlangsung dari h. 77 s.d. h. 95, dan cabang kedua adalah digresi-digresi yang muncul di sela-sela cerita antara Cok dan Yasmin. Apabila dibuat bagan, cerita bercabang itu akan tampak sebagai berikut.

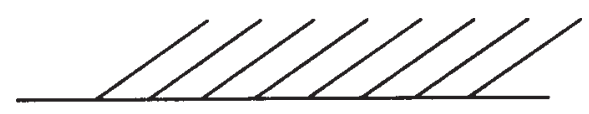

Dengan bagan yang seperti itu tampaklah bahwa cabang-cabang cerita membentuk struktur ontologis tersendiri yang antara satu dengan lainnya ada yang saling berhubungan dan ada yang tidak saling berhubungan, merupakan cerita tersendiri. Meskipun demikian, garis yang menghubungkan cabangcabang cerita itu merupakan cerita besamya, yang dalam hal ini adalah dialog antara Cok dan Yasmin, dengan sudut pandang Cok. Dengan begitu maka tengah-tengah, yang merupakan persimpangan di antara cabang cerita dan cerita besar tidak dikeluarkan, tetapi diberi porsi cerita masing masing. Dengan itu pula dapat diketahui bahwa cabang cerita membentuk struktur ontologis tersendiri, dan dengan demikian cerita bercabangnya - tidak seperti dalam cerita modem yang cenderung dihindarimenjadi hadir.

Pengertian dari ke(tidak)berakhiran dalam fiksi postmodern menunjuk pada pengakhiran cerita. Dalam novel Larung, pengakhiran yang bersifat ke(tidak)berakhiran terjadi karena ada tiga cerita yang memiliki kesa tuan di dalam dirinya sendiri, tetapi sekaligus memiliki kaitan di antara satu dengan lainnya. Cerita pertama berlangsung dari halaman 1 s.d. 74, cerita kedua dari halaman 76 s.d. 188, dan cerita ketiga dari halaman 191 s.d. 259.

Selain menunjukkan ciri-ciri bentuk cerita dunia-dunia di bawah penghapusan, novel Larung juga menunjukkan ciri-ciri bentuk cerita dunia-dunia kotak Cina.

Dalam hal cerita yang berstruktur ke arah kemunduran yang tak terbatas, di dalam Larung tidak ditemukan. Namun demikian, ada varian lain dari pola yang seperti itu. Ceritanya bukan gerakan mundur yang terus-menerus, tetapi mundur ke belakang dan kemudian bergerak ke masa kini yang dilanjutkan dengan cerita ke masa depan. Hal itu tampak pada halaman 26-31 yang menceritakan pengalaman pengalaman Larung di masa lalu hingga is bisa menemukan alamat Suprihatin. 
Struktur cerita trompe-l'oeil muncul pada halaman 177-181 yang menceritakan pikiran Saman yang berlompatan seperti percik-percik listrik dalam sebuah korslet yang panjang. Korslet itu kemudian terbawa ke dalam alam mimpi, dan kemudian alam mimpi itu diceritakan secara detail. Padahal, mimpi tersebut sesungguhnya tidak ada. la menjadi ada karena dilukiskan oleh pengarang sebagai ada. Karenanya, penggambaran mimpi itu kemudian membangun struktur ontologis tersendiri, yang berbeda dari struktur ontologis dunia pikiran Saman yang sebenarnya.

Struktur cerita yang menunjukkan keterpesonaan-keterpesonaanyang aneh tampak pada halaman 140-142 yang menggambarkan terjadinya kekacauan perbedaan antara ilusi dan kenyataan yang terjadi pada Laila yang kemudian dijadikan pijakan bagi cerita berikutnya mengenai hal yang sama tetapi dialami oleh tokoh lain, yaitu Shakuntala yang kebetulan juga bernama Shakuntala.

Sama-sama bercerita tentang kekacauan antara ilusi dan kenyataan, tetapi kedua cerita itu dialami oleh tokoh yang berbeda dan menyangkut hal yang berbeda. Pada Laila ilusi tentang Sihar, pada ibu Shakuntala ilusi tentang anak laki-lakinya, jenis kelamin Shakuntala, dan Tuhan. Lompatan dari cerita yang satu mengenai kekacauan antara ilusi dengan kenyataan ke cerita yang lain mengenai hal yang sama merupakan lompatan dari ontologis yang satu ontologis yang lain.

Struktur cerita dalam bentuk tokohtokoh dalam pencarian pengarang tampak dalam cerita Suprihatin (h. 36) tentang penghuni gua kalong yang adalah mereka yang dikalahkan, tetapi memiliki mimpi malam hari. Yang dimaksudkannya adalah mereka yang datang dari dunia cerita, yaitu Calon Arang, Ratna Manjali, Gandi, Lendi, Guyang, dan Lar- ung (murid Calon Arang). Calon Arang dikalahkan oleh Mpu Baradah, Ratna Manjali dikalahkan oleh Mpu Bahula, Gandi, Lendi, Guyang, dan Larung adalah murid Calon Arang yang juga dikalahkan oleh Mpu Baradah. Dikalahkannya Calon Arang oleh Mpu Baradah dan ditaklukkannya Ratna Manjali oleh Mpu Bahula dikatakan sebagai memiliki kesejajaran dengan cerita sebelumnya tentang Uma yang menjelma menjadi Durga karena kesuciannya dinodai oleh penarik sampan. Tokoh-tokoh yang datang dari cerita lain ini, oleh Suprihatin dikatakan sebagai menempati gua kalong yang juga menjadi tempat berlalunya mayatmayat korban pembantaian pada tahun 1966. Tidak demikian halnya dengan Weksirsa dan Mahisawadana yang telah bertobat di hadapan Mpu Baradah. Dalam cerita ini pengarang memainkan Suprihatin pada level ontologis yang berbeda dari tokohtokoh dari cerita lain di atas dan memainkan tokoh-tokoh di atas untuk membangun sebuah dunia yang sejajar, yaitu mereka yang dikalahkan, baik Calon Arang, Ratna Manjali dan muridmuridnya Calon Arang, Durga, ataupun mereka yang menjadi korban pembataian tahun 1966. Mereka semua adalah orang-orang yang dikalahkan, tetapi memiliki mimpi malam hari.

Struktur cerita yang berbentuk fiksifiksi bukan kepalang atau mise-enabyme tampak pada cerita tentang Adnyani yang sulit dibedakan dengan Calon Arang. Kesulitan dalam membedakan di antara mereka karena Adnyani adalah pengikut Calon Arang (h. 12-13).

Dalam cerita itu antara Adnjani dan Calon Arang (Ni Rangda) berada dalam proses penyatuan sehingga keduanya sulit dibedakan: mana Adnjani dan mana Calon Arang. Peristiwa itu menunjukkan terjadinya proses penyatuan dua ontologi yang berbeda: ontologi dunia 
nyata, yaitu dunia Adnjani, dengan ontologi dunia cerita, dunia yang tertulis dalam lontar, yaitu dunia Calon Arang.

Struktur cerita yang berbentuk yang riil tampak pada digambarkannya pengaruh pementasan tari Shakuntala terhadap perasaan Laila. Dunia pementasan yang memiliki struktur ontologis tersendiri-seperti halnya film dalam gedung bioskop atau berbagai macam acara yang ditayangkan di televisi ternyata memiliki pengaruh pada dunia di luar pemanggungan, yaitu dunia nyata (h. 126). Pengaruh pementasan tari Shakuntala terhadap Laila menunjukkan terjadinya intervensi ontologi dunia pemanggungan ke dunia nyata. Intervensi itu pada gilirannya menghilangkan batas antara ontologi dunia maya dan dunia nyata.

Struktur cerita yang riil" juga tampak pada tokoh Yasmin. Yasmin mengalami kerancuan antara kenyataan dengan keinginan. Keinginan adalah suatu struktur ontologis tersendiri yang berada di dalam angan-angan, yang bisa jadi hanya bersifat fiktif saja, dan kenyataan juga suatu struktur ontologis tersendiri yang terjadi di sini dan kini. Pada diri Yasmin kedua struktur ontologis itu muncul secara serentak diri Yasmin sehingga Yasmin merasakan suatu kejanggalan ketika keduanya harus dibedakan (h. 154-155).

\section{Simpulan}

Berdasarkan pembahasan yang telah dikemukakan, dapat disimpulkan bahwa dalam hal konstruksi, novel Larung menunjukkan ciri-ciri kepostmodernan. Konstruksi novel Larung muncul dalam struktur-struktur yang bersifat ontologis.

Dalam hal dunia-dunia di bawah penghapusan, novel Larung methunculkan struktur-struktur ontologis yang berkaitan dengan, tengah tengah yang dikeluarkan, cerita bercabang, dan pengertian tentang ke(tidak)berakhiran.

Dalam hal dunia-dunia kotak Cina, novel Larung memunculkan strukturstruktur ontologis yang berkaitan dengan menuju ke kemunduran yang tak terbatas, trompe l'oeil, keterpesonaanketerpesonaan yang aneh atau metalepsis, tokoh-tokoh yang dicari pengarang, fiksi-fiksi bukan kepalang, dan yang nyata. Namun, berkaitan dengan menuju ke kemunduran yang tak terbatas, novel Larung menunjukkan ciri yang sebaliknya: mundur ke belakang dalam rangka menceritakan hal-hal yang terjadi sebelumnya dalam alur menuju ke kekinian.

\section{Daftar Pustaka}

Dewanto, Nirwan. 1991. "Kebudayaan Indonesia: Pandangan 1991", Prisma, No. 10 Tahun XX.

Featherstone, Mike. 1993. "Modem dan Pascamodem: Tafsiran dan Tetapan", Prisma, Januari 1993

Huyssen, Andreas. 1990. "Mapping the Postmodern", Culture and Society Contemporary Debates, Jeffrey C. Alexander and Steven Seidman, ed., New York: Cambridge University Press.

Jacobson, Roman. 1994. “The Dominant", Language in Literature, Krystyna Pomorska, ed., cet. ke-5, United States of America: The Jacobson Trust

McHale, Brian. 1991. Postmodernist Fiction, London and New York: Routledge

M. Gottdiener. 1994. "Semiotics and Postmodernism", Postmodernism and Social Inquiry, edited by David R. Dickens and Andrea Fontana, foreword by Fred Dallmayr, New York London: The Guilford Press

Robertson, Roland. 1996. "Globality, Globalization and Transdisciplinarity", Theory, Culture and Society 1996 
(Sage, London, Thousand Oaks and New Delhi), Vol. 13(4).

Sarup, Madan, 1993. An Introductory

Guide to Post-Structuralism and Postmodernism, Second edition, Athens: The University of Georgia Press.
Sugiharto, I. Bambang. 1996. Postmodernisme Tantangan Bagi Filsafat, Yogyakarta: Kanisius.

Utami, Ayu. 2001. Larung, Jakarta: Gramedia 